In the preface the author regrets that he has no teaching experience, and that because of this the book contains no examples. But this is by no means the only disappointing feature. All the illustrations are line diagrams, and several of them lack detail or are incomplete. Although the author stresses the importance of correct correlation of units, he fails in many places to follow his own advice. On some occasions the author's expressions are not well chosen. In its present form the work should be used for reference and with some caution, but after careful revision it should become a standard text-book for undergraduate use.

S. WEINTROUB

\section{JUVENILE CRIME AND ITS CAUSES}

\section{Delinquency and Human Nature}

By D. H. Stott. Pp. viii +460 . Carnegie United Kingdom Trust, 1950.)

DRING the Second World War it was predicted by several psychologists that its termination would be followed, not by a diminution in the figures for juvenile delinquency, but by a further increase. Accordingly, in 1945 it was suggested to the Carnegie United Kingdom Trust that an intensive study of a group of adolescent offenders should be undertaken by an investigator who might be allowed to reside at an approved school as though he were an ordinary member of the staff. Mr. D. H. Stott has spent four years studying delinquents in this way; and the Trust has now published a full report of his observa. tions and conclusions.

From a scientific point of view, one of the most interesting sections of Mr. Stott's report is his critical examination of the procedures that could be followed in researches of this type. He makes out a convincing case for using "a standard technique of investigation". In drawing up his own scheme he owes much, he says, to the advice of Prof. C. A. Mace on the logical nature of the issues involved and to Sir Cyril Burt for "schooling in method". Burt's method consisted in the combination of a case-study procedure, to elucidate causation, with a statistical procedure, to verify causal hypotheses. Mr. Stott, however, considers that the two modes of attack should be separated. He deplores the "insightless use of statistics" by recent psychiatric writers and urges that a systematic and intensive investigation of apparent causes should precede any attempt to collect numerical data on a wider scale. His present inquiry has therefore been limited to a detailed study of a hundred residents in a single approved school. This, however, he hopes will be supplemented later on by a more extensive survey to secure what he calls "statistical verification of sectional hypotheses".

A special merit of Mr. Stott's approach is that he treats crime as essentially a social and psychological problem, not as a psychiatric problem. Recent attempts to interpret delinquent behaviour in quasimedical terms are, he maintains, largely due to the fact that the psychiatrists dealing with such cases generally have no basic knowledge of normal psychology, and consequently tend to envisage the problems that they encounter in terms of the pathological processes with which they are more familiar. "They cling to the ingenuous assumption, borrowed from their training in medicine, that what they regard as psychopathic states are due to some disease." $\mathrm{He}$ himself looks upon delinquency, not as a form of mental illness to be studied by the medical psychologist, but rather as an intelligible mode of reaction to an intolerable situation.

Nevertheless, he, too, seems more familiar with psychoanalytic studies of the abnormal than with the psychology of normal human nature. As a rule, he sets down his observations and his conclusions in the improvised and figurative phraseology of the psychiatrist rather than in the more rigorously defined terminology of the psychologist; and his conclusions about the causation of delinquency are admittedly based on analogies drawn from theories about neurotic disorder. Delinquent breakdown, he considers, is similar to nervous breakdown-to shellshock, for example. There is first a rising tension set up by some long-standing situation which becomes at last almost unbearable. With his own cases this situation usually arose out of the unhappy emotional relations between the child and his parents, so that "the problem of delinquency is in great measure the problem of the unsatisfactory family". Then, when the child's nervous exhaustion has almost reached its tolerance-limit, a crisis factor-some spectacular event, such as a parental quarrel, a war-time shock or a narrow escape from a physical accident that leaves behind a chronic fear-seems to precipitate the actual lapse, which usually takes the form of a blind plunge into some wild or daring adventure. After all, therefore, so Mr. Stott goes on to suggest, a plausible case may be made out for treating the habitual offender "as a sick person".

However, the whole theory admittedly rests on what he terms his "very tentative hypothesis of nervous resources", supplemented by the psychoanalytic notion of avoidance-reactions. There can be little doubt that some delinquent careers start in this way : Mr. Stott's own examples, as well as the work of earlier investigators, provide convincing evidence to this effect. But what is far more questionable is his attempt to generalize this explanation in a manner which tacitly assumes that delinquency is a single specific condition due always to one and the same type of cause. The vast majority of the cases studied by Mr. Stott had been removed to an approved school just because their home situation was so unsatisfactory. How often would the same factors be found among delinquents who had not been removed on this account?

If we view the problem from the point of view of the biologist rather than from that of the pathologist, is it not possible, without invoking any new hypothesis about "nervous resources", to explain most of the early delinquencies of the young as the result of perfectly normal impulses? When a kitten steals meat from the larder, fights the cat next door or runs away and gets lost, we do not postulate a prolonged intolerable strain at home, with a crisis-factor to account for the final breakdown. The natural impulses of young children are of much the same general type; and, if uncorrected, may easily get fixed as habits. The problem rather is: What methods of moral training can be successfully adopted to forestall this uncivilized behaviour, and why do existing methods so often fail ? If we may judge by published statistics, the after-histories of child guidance cases seem to show that, although a few delinquents of psychoneurotic type undoubtedly benefit by medical treatment, the majority respond far better to some form of moral re-education than to 'therapeutic treatment' in the psychiatric sense. 